\begin{tabular}{|c|l|}
\hline Title & Longevity of captive shrews in Hokkaido \\
\hline Author(s) & Ohdachi, Satoshi \\
\hline Citation & $\begin{array}{l}\text { Mammal Study, 21(1),65-69 } \\
\text { https://doi.org/10.3106/mammal study.21.65 }\end{array}$ \\
\hline Issue Date & 1996 \\
\hline Doc URL & http://hdl.handle.net/2115/44403 \\
\hline Type & article \\
\hline File Information & MS21-1_65-69.pdf \\
\hline
\end{tabular}

Instructions for use 
Short Communication

\title{
Longevity of captive shrews in Hokkaido
}

\author{
Satoshi OHDACHI* \\ Institute of Low Temperature Science, Hokkaido University, Kita-ku, Sapporo O60, Japan \\ Fax. 011-706-7142, E-mail. ohdachi @ bio. hokudai. ac. jp
}

Information concerning the longevity of animals is invaluable for various biological studies. The longevity of some shrew species (Soricidae) has been reported both from the wild and in captivity (Churchfield 1990). Churchfield (1990) also showed that captive shrews tended to live longer than those in the wild in general, because of the preferential conditions in the laboratory. For a shrew species of Hokkaido, Inoue (1990) reported a maximum estimated life span of 511 days for Sorex unguiculatus in the field. For S. unguiculatus in captivity, Yokohata (1989) reported a maximum keeping period of 493 days and estimated that the oldest might live for 710-830 days. However, longevity for Sorex caecutiens and S. gracillimus, other common soricine species in Hokkaido, is little known. In the present study, all the three species were kept in the laboratory, slightly modifying Yokohata's (1989) rearing method. The purpose of the present study is to report the longevity of captive Sorex caecutiens and $S$. gracillimus along with that of $S$. unguiculatus.

\section{MATERIALS AND METHODS}

\section{Animals examined}

Shrews were collected in June 1992 and 1993 from Tomakomai (Yufutsu moor), and in June 1992 and August 1993 from Horonobe near the Teshio Experimental Forest of Hokkaido University. The methods of capturing shrews were essentially the same as those described by Ohdachi (1992). Seventeen $S$. caecutiens, 22 S. gracillimus, and 28 S. unguiculatus were used for analysis.

The animals examined for the present report were originally used for behavioral laboratory experiments (Ohdachi 1994, 1995a, b). During the experiments, laboratory conditions were maintained at either $16 \mathrm{~L} 8 \mathrm{D}, 20^{\circ} \mathrm{C}$ or $10 \mathrm{~L} 14 \mathrm{D}$, $5-15^{\circ} \mathrm{C}$. After the experiments, the animals were kept in order to record their longevity, but photoperiodic cycle was no longer controlled. Mixed paste diets of pork meat, pork liver, canned tuna, dog food and rabbit pellets were supplied every day. In addition to the mixed pastes, living mealworms (Tenebrio sp.), living earthworms and frozen silkworm pupae (Bombyx mori) were given occasionally. The supplementary natural foods seemed to contribute to the

*Research Fellow of the Japan Society for the Promotion of Science 
greater longevity of these captive shrews. Animals that were sexually immature when captured experienced neither copulation, pregnancy, nor parturition during their lives. The most significant difference between Yokohata's (1989) rearing methods and those in the present study was that I always kept cages clean while Yokohata did not. See Ohdachi (1994) for more detailed methods.

\section{Estimation of Longevity}

Two methods for estimating longevity were used depending on the age of the shrews when captured ; the first is for young of the year, and the second for individuals that have overwintered. Ages at capture were assessed on the basis of wear to hair and body weight (Abe 1958, Ohdachi and Maekawa 1990).

The young shrews that were caught were all considered to be fully independent from their mothers. Inoue (1990), who reviewed the literature concerning lactation periods ( $\approx$ the period from birth to independence) of six soricine species (Sorex cinereus, S. vagrans, S. araneus, Cryptotis parva, Neomys fodiens and Blarina brevicauda), concluded that the lactation periods ranged from 16 to 30 days. Inoue (1990) also estimated that the lactation period of S. un guiculatus in the field averaged 27.6 days. Churchfield (1990) considered that the period from birth to complete independence in $S$. araneus lasted 25 days. In the light of these studies, it is assumed that for the three soricine species in Hokkaido, the period from birth to independence averages 25 days. Therefore, in order to estimate the life span of the individuals that were captured as youngsters, 25 days were added to their survival periods in the laboratory, thus, giving a minimum estimate of longevity, as 25 days is the estimated minimum age of the young animals captured from the wild.

Most soricine species bear young from spring to autumn (mostly in spring) and new-born individuals, usually, do not become sexually mature until the following spring (e.g., Crowcroft 1957, Churchfield 1990). In S. unguiculatus of central Hokkaido, most females bear offspring between April and September (Inoue 1990). Pregnant female $S$. caecutiens and S. gracillimus were recorded no later than in late September, although some females are known to survive until November (Ohdachi unpublished data). It is assumed, therefore, that the last possible birth date of shrews in Hokkaido is October 1st. Thus, in order to estimate the age of shrews that were captured after they had overwintered (i.e., sexually mature individual), the period from October 1st of the previous calendar year to the date of capture was added to the period survived in the laboratory. Again, this method of estimation provides only a minimum life span, since the estimated period survived in the wild is also a minimum.

\section{RESUlTS AND Discussion}

Most wild-captured shrews were successfully introduced into the laboratory, although several died during transportation. Two out of $17 \mathrm{~S}$. caecutiens, 2 out of 22 S. gracillimus, and 4 out of 28 S. unguiculatus which were success- 
fully introduced to the laboratory died within the first week. Most $S$. caecutiens and $S$. unguiculatus which survived the first week in the laboratory survived for more than 100 days. In contrast, 13 out of the 20 surviving $S$. gracillimus died within 100 days (mean $=52.4$ days). In most cases, animals died suddenly without apparent symptoms, and the cause of death were unknown.

The maximum estimated life span for S. caecutiens was 609 days, for $S$. gracillimus 419 days and for S. unguiculatus 946 days (Fig. 1). The maximum life span for $S$. caecutiens would, in fact, have been longer, had it not died as a result of its water supply failing. The maximum of 946 days for S. unguiculatus reported here is one of the longest life span records among the Soricinae (Churchfield 1990).

Churchfield (1990) pointed out that larger shrew species tended to live longer than smaller species, which seems to be related to activity and basal metabolic rates. S. unguiculatus is the largest species and $S$. gracillimus the smallest among the three species in Hokkaido, and in the present study $S$. gracillimus tended to live shorter lives than the other two species (Fig. 1). It seems, therefore, that interspecific differences in the maximum estimated life spans of Hokkaido shrews seems to be related to body size, as pointed out by Churchfield (1990).

Acknowledgments : Students at the Institute of Low Temperature Science and the Laboratory of Applied Zoology, Faculty of Agriculture, Hokkaido University, especially Y. Yamaga and K. Nishimura, kindly assisted me in taking care of the shrews. T. Segawa and H. Ishii, and other technicians of the Institute made devices for keeping the shrews. Dr. K. Sasa, Dr. K. Ishigaki, T. Shida, A. Nishihara, and H. Takemoto supported my field work, and Dr. Y. Yokohata made useful suggestions for keeping shrews. I express my deep gratitude to all of them. 


\section{S. caecutiens}

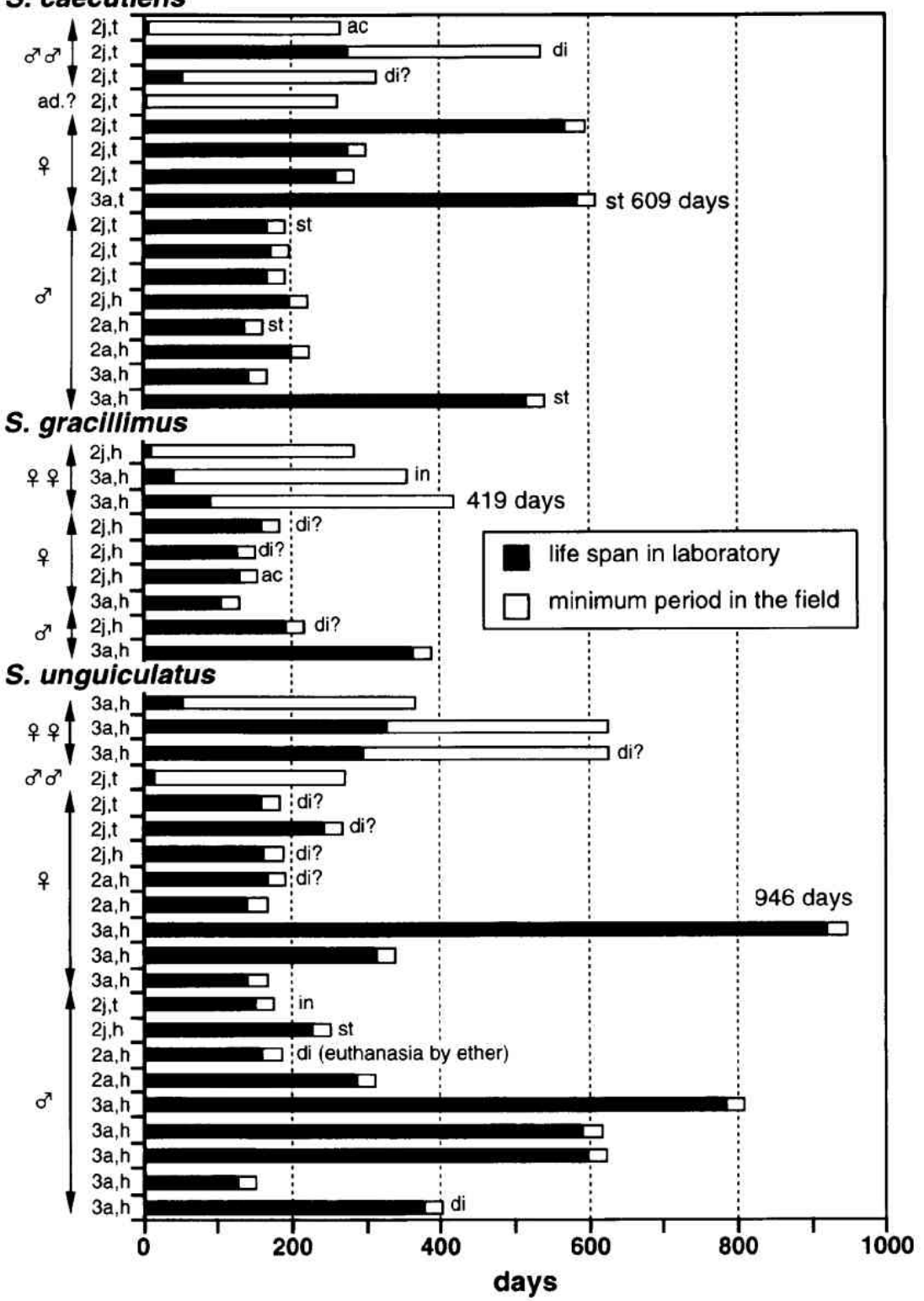

Fig. 1. The estimated longevity of three species of Sorex in captivity in Hokkaido. Black bars indicate the actual period shrews survived in the laboratory, and white bars indicate the estimated minimum duration in the field (see text for calculation). Young animals surviving fewer than 100 days in the laboratory were omitted from the figure. Letters to the left of the bars indicate dates of capture and localities (" $2 \mathrm{j}, \mathrm{t}$ " = June 1992 in Tomakomai, " $2 \mathrm{j}, \mathrm{h}$ " = June 1992 in Horonobe, "2a, h" = August 1992 in Horonobe, and " $3 \mathrm{a}, \mathrm{h}$ " = August 1993 in Horonobe). Letters to the right of the bars record the causes of death ( $\mathrm{ac}=$ accidental kill, $\mathrm{di}=$ disease, st $=$ starvation or a lack of water, in $=$ injured, and no letter $=$ unknown). Double sex symbols denote sexually mature animals when captured, and single ones immature animals (ad.? = sex-unknown but mature individual). 


\section{REFERENCES}

Abe, H. 1958. Individual and age variation in two species of genus Sorex, Insectivora in Hokkaido. Mem. Facul. Agr., Hokkaido Univ. 3: 201-209.

Churchfield, S. 1990. The Natural History of Shrews. A \& C Black Ltd., London, 178 pp.

Crowcroft, P. 1957. The Life of the Shrew. Max Reinhardt, London, 166 pp.

Inoue, T. 1990. Study of Social Structure and Life History of Sorex unguiculatus Dobson. A Special Reference to Sexual Variation in Dispersal of the Young. Ph. D. dissertation at the Graduate School of Agriculture, Hokkaido University, Sapporo, $134 \mathrm{pp}$. (In Japanese).

Ohdachi, S. 1992. Home ranges of sympatric soricine shrews in Hokkaido, Japan. Acta Theriol. $37: 91-101$.

Ohdachi, S. 1994. Total activity rhythms of three soricine species in Hokkaido. J. Mammal. Soc. Japan $19: 89-99$.

Ohdachi, S. 1995a. Burrowing habits and earthworm preferences of three species of Sorex in Hokkaido. J. Mammal. Soc. Japan $20: 85-88$.

Ohdachi, S. 1995b. Comparative Ecology and Ethology of Sympatric Soricine Shrews in Hokkaido : A Special Reference to Their Interspecific Interactions. Ph. D. dissertation at the Graduate School of Science, Hokkaido University, Sapporo, 116 pp.

Ohdachi, S. and K. Maekawa. 1990. Relative age, body weight, and reproductive condition in three species of Sorex (Soricidae; Mammalia) in Hokkaido. Res. Bull. Coll. Exp. For., Facul. Agr., Hokkaido Univ. $47: 535-546$.

Yokohata, Y. 1989. Rearing of big-clawed shrew, Sorex unguiculatus. Honyurui Kagaku [Mammalian Science] $29: 23-28$ (In Japanese with English summary). 